\title{
Surgical Treatment of the Ruptured Aneurysm of the Aortic Sinus of Valsalva
}

\author{
Ken-ichi Asano, M. D., Masahiko Washio, M.D., Kota Shrozaki, \\ M.D., Shoji Eguchi, M.D., Hideo Matsuzawa, M.D., and \\ Tetsunosuke Matsukawa, M.D.
}

\begin{abstract}
2 UPTURED aneurysm of the aortic sinus of Valsalva has been interested $\mathcal{L}$ because of its characteristic clinical features, such as the onset and the cardiac murmurs, and its extremely poor prognosis. The incidence of this lesion has been stated to be very rare, especially in the English literature, but it seems to be somehow more frequent in Japan. The purpose of this paper is to report the clinical experience of the ruptured aneurysm of the aortic sinus in the Department of Thoracic Surgery of the Niigata University Hospital and to discuss clinicopathologic and surgical aspects.
\end{abstract}

\section{Clinical Materials}

Five cases of the ruptured aneurysm of the aortic sinus have been experienced and they were all male, and from 14 to 32 years of age.

Table I. History and Symptoms of the Onset

\begin{tabular}{|c|c|c|c|c|c|c|}
\hline Case & Age & Sex & Previous History & Onset & Initial Symptoms & $\begin{array}{l}\text { Symptoms on } \\
\text { Admission }\end{array}$ \\
\hline 1 & 27 & $\mathbf{M}$ & $\begin{array}{l}\text { Heart disease not } \\
\text { detected }\end{array}$ & $\begin{array}{l}3 \text { years ago, } \\
\text { definitely }\end{array}$ & $\begin{array}{l}\text { Nocturnal back- } \\
\text { pain, edema in } \\
\text { morning }\end{array}$ & Back-pain \\
\hline 2 & 18 & $\mathbf{M}$ & $\begin{array}{l}\text { Murmurs indicat- } \\
\text { ed at } 6 \text { years } \\
\text { of age }\end{array}$ & $\begin{array}{l}1 \text { year ago, } \\
\text { gradually }\end{array}$ & $\begin{array}{l}\text { Palpitation and } \\
\text { shortness of } \\
\text { breath after } \\
\text { exercise }\end{array}$ & $\begin{array}{l}\text { Same to initial } \\
\text { symptoms }\end{array}$ \\
\hline 3 & 14 & M & $\begin{array}{l}\text { Murmurs indicat- } \\
\text { ed at primary } \\
\text { school age }\end{array}$ & $\begin{array}{l}3 \text { weeks before } \\
\text { admission, } \\
\text { suddenly }\end{array}$ & $\begin{array}{l}\text { Chest pain, } \\
\text { dyspnea }\end{array}$ & $\begin{array}{c}\text { Palpitation, } \\
\text { dyspnea }\end{array}$ \\
\hline 4 & 32 & $\mathbf{M}$ & $\begin{array}{l}\text { Heart disease not } \\
\text { detected }\end{array}$ & $\begin{array}{l}6 \text { months ago, } \\
\text { suddenly }\end{array}$ & Dyspnea & $\begin{array}{l}\text { Palpitation, } \\
\text { dyspnea after } \\
\text { exercise }\end{array}$ \\
\hline 5 & 31 & $\mathbf{M}$ & $\begin{array}{l}\text { Heart discase not } \\
\text { detected }\end{array}$ & $\begin{array}{l}4-5 \text { years ago, } \\
\text { gradually }\end{array}$ & $\begin{array}{l}\text { Palpitation, short- } \\
\text { ness of breath } \\
\text { after exercise }\end{array}$ & Chest agony \\
\hline
\end{tabular}

From the Department of Thoracic Surgery, Faculty of Medicine, University of Niigata, Niigata. Received for publication February 20, 1967. 
In the previous history, cardiac murmurs had been detected in only 2 patients (Cases 2 and 3) before the onset of the symptoms, and there was nothing special, possibly related to this disease in their family histories.

The onset of the symptoms occurred from several years to 3 weeks before admission, and the symptoms appeared as an attack in 2 cases (Cases 3 and 4), definitely but not so acutely in one (Case 1) and rather gradually but insidiously in 2 (Cases 2 and 5). Initial symptoms on the onset were palpitation, shortness of breath after exercise, dyspnea, chest and back pain and edema. Patients were all severely disabled and had been treated medically in other hospital before entering the University Hospital (Table I).

\section{Glinical Findings}

Congestive heart failure was demonstrated in Cases 3 and 4 at the time of admission. The liver was palpable in all patients from 1 to 5 finger breadths below the right costal margin, ascites and pleural effusion were accumulated in Case 4 and ascites appeared in Case 3 later during the hospital course. Peripheral signs of the aortic insufficiency were evident and widening of the pulse pressure was demonstrated in all patients.

Cardiac examinations revealed the loud $(5 / 6$ or $6 / 6)$ to-and-fro or continuous murmurs at the 3rd or 4 th intercoastal space of the left sternal border which were widely radiated and associated with intense precordial thrills (Table II). Marked cardiomegalies with increased pulmonary vascularization were found in chest X-ray films of all patients, and cardiothoracic ratios were ranged from 58.1 per cent to 72.3 per cent (Fig. 1).

The electrocardiographic findings were various; left ventricular hypertrophy in Cases 2 and 5, biventricular hypertrophy in Case 1, and myocardial damage in Cases 4 and 3 who were in congestive heart failure. In Case 4 the incomplete right bundle branch block and the low-voltage were noted in addition. No specific finding was revealed in reference to syphilis, rheumatic

Table II. Clinical

\begin{tabular}{|c|l|c|c|c|c|c|}
\hline Case & Murmurs & Thrills & $\begin{array}{c}\text { Blood pressure } \\
\mathrm{mm} . \mathrm{Hg} \text { (postop.) }\end{array}$ & Edema & Ascites & Hepatomegaly \\
\hline 1 & $\begin{array}{l}5 / 6 \text { to-and- } \\
\text { fro murmurs }\end{array}$ & + & $140 / 68(120 / 64)$ & $\mathrm{No}$ & No & $1 \mathrm{FB}$ \\
\hline 2 & $\begin{array}{l}5 / 6 \text { to-and- } \\
\text { fro murmurs }\end{array}$ & + & $180 / 0(110 / 70)$ & No & No & $1.5 \mathrm{FB}$ \\
\hline 3 & $\begin{array}{l}\text { to-and-fro } \\
\text { murmurs }\end{array}$ & + & $118 / 0$ & No-yes & No-yes & $1 \mathrm{FB}-5 \mathrm{FB}$ \\
\hline 4 & $\begin{array}{l}5 / 6 \text { to-and- } \\
\text { fro murmurs }\end{array}$ & + & $130 / 0(120 / 70)$ & No & Yes & $5 \mathrm{FB}$ \\
\hline 5 & $\begin{array}{l}6 / 6 \text { continuous } \\
\text { murmurs }\end{array}$ & + & $195 / 55(140 / 80)$ & No & No & $1 \mathrm{FB}$ \\
\hline
\end{tabular}




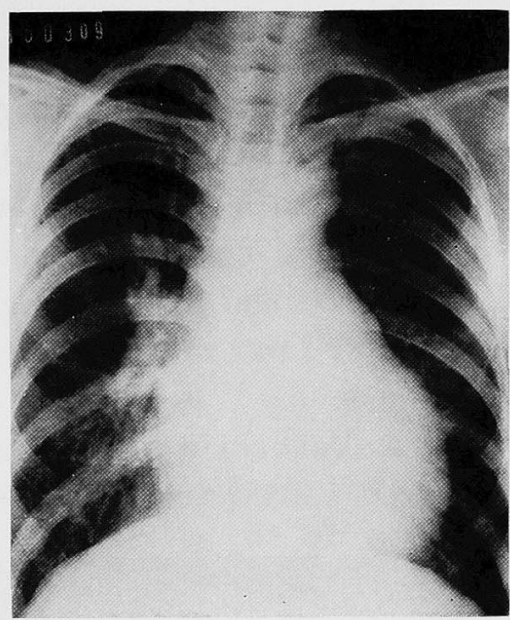

Case 1

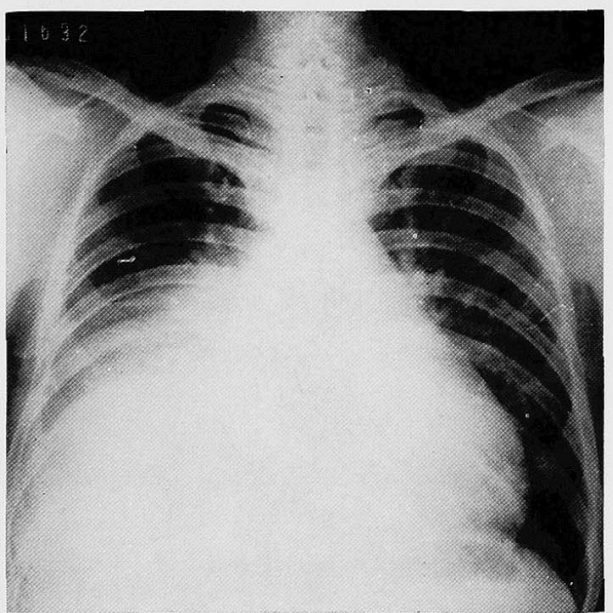

Case 4

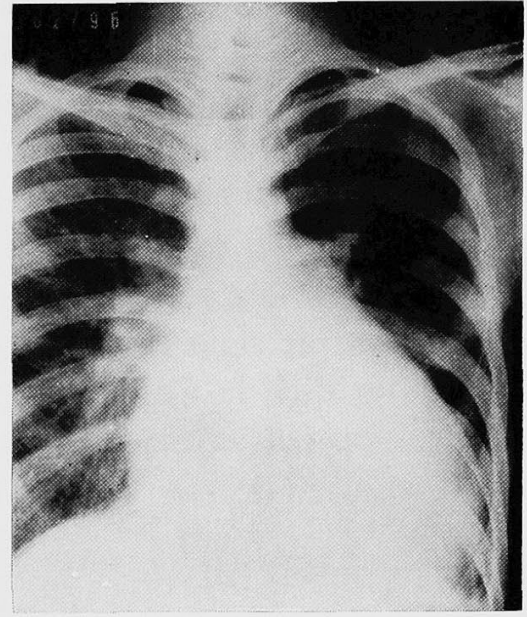

Case 2

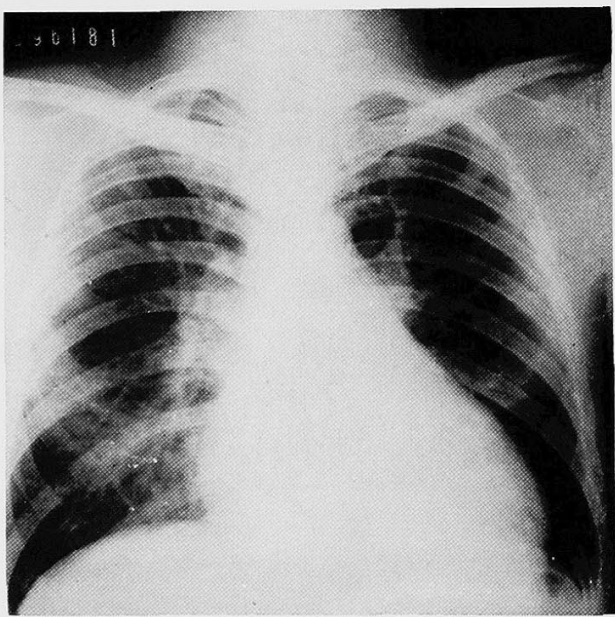

Case 5

Fig. 1. Preoperative chest X-ray films.

Findings

\begin{tabular}{|c|c|c|c|c|c|c|}
\hline $\begin{array}{l}\text { Congestive } \\
\text { heart failure }\end{array}$ & $\begin{array}{l}\text { CTR \% } \\
\text { (postop.) }\end{array}$ & EGG & STS & GRP & RA & $\begin{array}{l}\text { ASLO } \\
\text { (Todd) }\end{array}$ \\
\hline No & $\begin{array}{c}58.1 \\
(51.6)\end{array}$ & $\mathrm{BVH}$ & - & - & - & 166 \\
\hline No & $\begin{array}{c}72.3 \\
(46.5) \\
\end{array}$ & $\mathrm{LVH}$ & - & - & - & No \\
\hline Yes & 70.6 & M. D. & - & - & - & 100 \\
\hline Yes & $\begin{array}{c}61.6 \\
(51.6)\end{array}$ & $\begin{array}{l}\text { M. D. } \\
\text { IRBBB } \\
\text { Low Volt. }\end{array}$ & - & - & - & 125 \\
\hline No & $\begin{array}{c}58.2 \\
(51.0)\end{array}$ & LVH & - & - & - & 100 \\
\hline
\end{tabular}


fever and bacterial endocarditis (Table II).

Right heart catheterization was performed in Cases 1 and 4, and demonstrated the left-to-right shunts at the level of the right ventricle or the right atrium and increased intracardiac pressures in the right sided heart (Table III). Retrograde aortography was carried out in all but Case 3, and early opacification of the pulmonary artery was demonstrated immediately after that of the ascending aorta in Cases 1 and 2, and regurgitant jet to the right ventricle from the right coronary sinus in Case 5, and direct opacification of the aneurysm itself in Case 4 (Fig. 2).

The ruptured aneurysm of the aortic sinus of Valsalva was diagnosed clinically in all patients. One of them, Case 3, who was the youngest, dete-

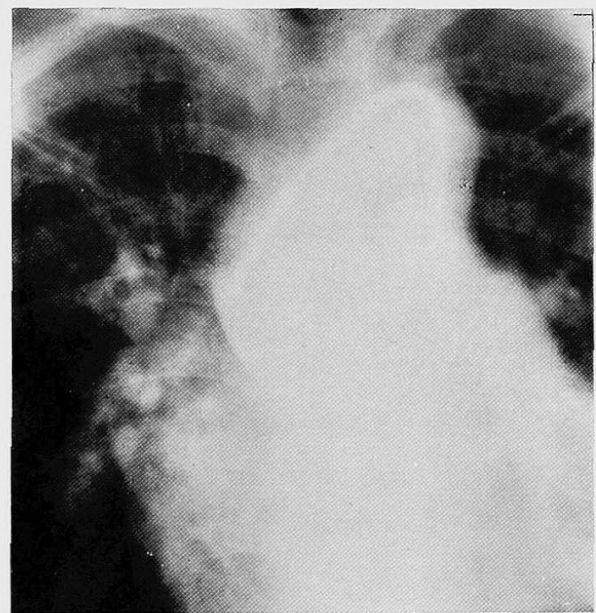

Case 1

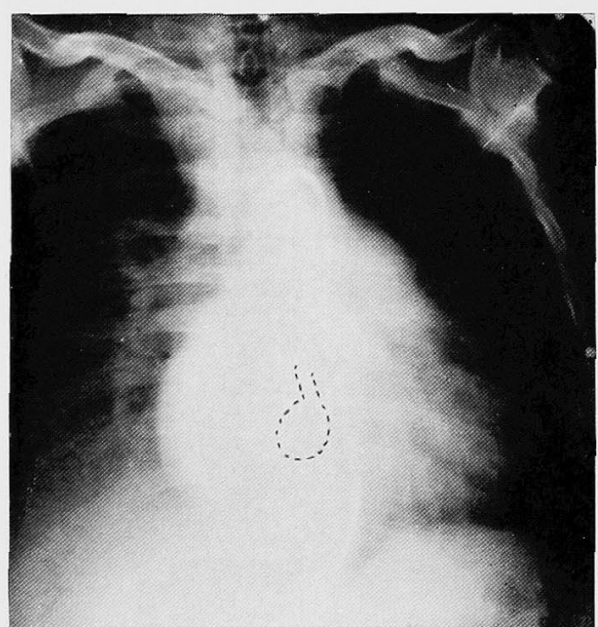

Case 4

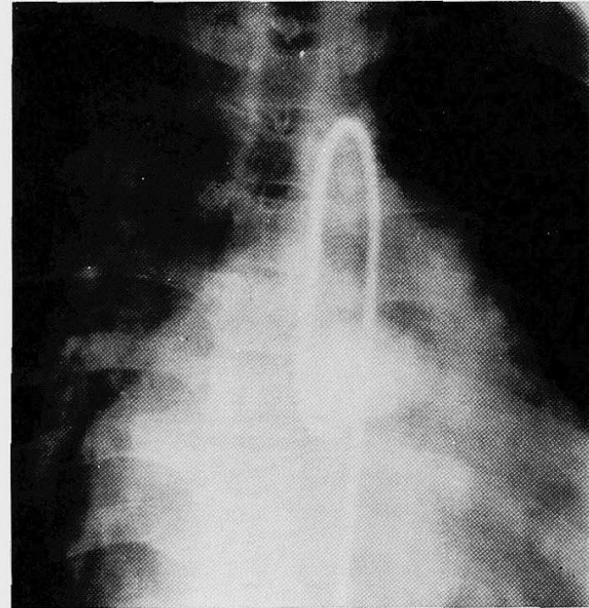

Case 2

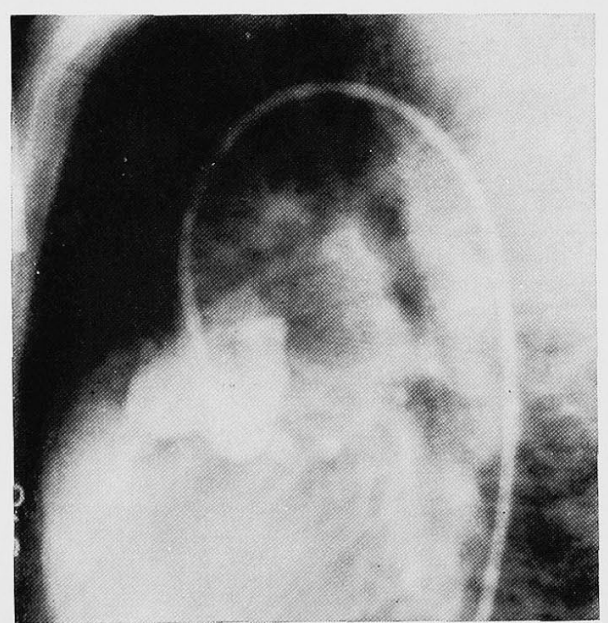

Case 5

Fig. 2. Preoperative retrograde aortograms. 
Table III. Findings of Right Heart Catheterization

\begin{tabular}{l|c|c|c|c}
\hline & \multicolumn{2}{|c|}{ Case 1 } & \multicolumn{2}{c}{ Case 4 } \\
\cline { 2 - 5 } & Pressure (mm. Hg) & $\mathrm{O}_{2}$ Vol. \% & Pressure (mm. Hg) & $\mathrm{O}_{2}$ Vol. \% \\
\hline Pulm. artery & $53 / 20$ & 15.90 & $56 / 24$ & 15.30 \\
Rt. ventricle & $65 / 6$ & 13.80 & $59 / 0$ & 16.20 \\
Rt. atrium & - & 13.25 & $33 / 10$ & 16.20 \\
S. V. C. & - & 13.75 & - & 11.30 \\
Fem. artery & - & 18.05 & - & 19.30 \\
Art. $\mathrm{O}_{2}$ sat. \% & & 98 & & 100
\end{tabular}

riorated progressively after admission inspite of the strenuous medical treatment, including the salt-restricted diet, digitalis and diuretics, and died only 2 months after the onset of the congestive failure with homoptysis, marked hepatomegaly and accumulation of ascites. The autopsy was refused.

\section{Operative Findings and Procedures}

Four patients were operated upon under cardiopulmonary bypass with perfusion hypothermia utilizing the rotating disc oxygenator and roller pumps of Pemco-Davila type.

Aneurysms, ruptured into the right ventricle were situated at the supracristal portion in Case 2 and at the infracristal portion in Cases 1 and 5, and
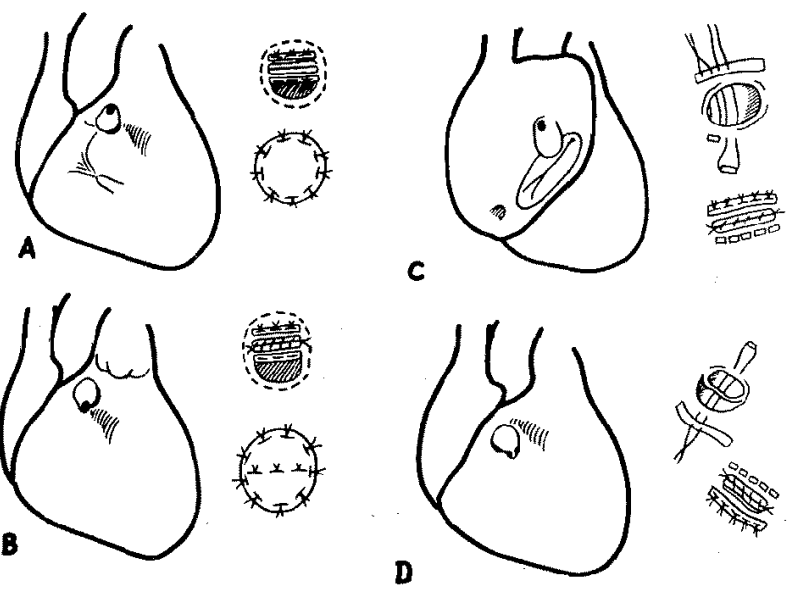

Fig. 3. Operative findings and procedures.

$A$ : case $1, B$ : case 2 . In both cases, the aortic sinus was excised and directly closed, and then a Teflon-patch was sutured to close the associated ventricular septum defect with or without reinforcement of the aortic sinus.

C: case 4, D : case 5. In both cases, mattress sutures with Teflon-pledgets and Dacron-spagetti-tubes were applied to close the defect. 
they were all associated with the ventricular septal defect adjacent to the lower margin of the aneurysm. In Case 4 the ruptured aneurysm was found at the right atrium near the anterior commissure of the tricuspid valve.

Aneurysms were excised at their bases and closed directly by mattress sutures with Teflon-pledgets and/or Dacron-spagetti-tubes, and moreover, ventricular septal defects were closed by Teflon-patch, also reinforcing the closure of the aortic sinus in Cases 1 and 2. In Case 5, the ventricular septal defect was closed simultaneously with the excised aortic sinus by mattress sutures with Teflon-pledgets and Dacron-spagetti-tubes (Fig. 3).

\section{Operative Results and Postoperative Courses}

Postoperative courses were all uneventful. Cardiomegalies were reduced and cardiothoracic ratios decreased 51.6 per cent to 46.5 per cent (Fig. 4). Blood pressures indicated definite decrease of the pulse pressure and peripheral signs of aortic insufficiency were completely subsided with disappearance of ascites and hepatomegaly.

Although 2 patients (Cases 1 and 2) revealed the systolic murmurs (2/6) at the 3rd intercostal space of the left sternal border without thrills I year and a half after discharge, there were no signs of recurrence of the ventricular septal defect or the residual aortic insufficiency, and they were all in good health.

\section{Discussion}

Ruptured or unruptured aneurysm of the aortic sinus of Valsalva is not so rare in Japan, and authors could collect about 150 operated cases by the end of 1966 in Japanese literature, ${ }^{1 /}$ including even 2 institutions experiencing more than 40 cases respectively. Taguchi ${ }^{1}$ reported that the incidence of this lesion, including unruptured aneurysms, was 3.1 per cent in all operated cardiac patients or 4.6 per cent in all patients of congenital heart disease with surgery. In our experiences, the incidence was 1.0 per cent in 500 patients in the former and was 1.3 per cent in 383 cases in the latter, respectively by January in 1967.

There have been stated 3 explanations about etiologic mechanisms of this lesion. The first is abnormal development of the embryologic bulbar ridges, resulting in a weakened aortic wall in the region of the adjacent sinuses of Valsalva. This theory, represented by Jones and Langley, ${ }^{2}$ is suitable to explain production of aneurysms of the right-coronary and the non-coronary sinuses, but it is rather difficult to explain the mechanism of congenital aneurysm involving the left coronary sinus. The second theory, 

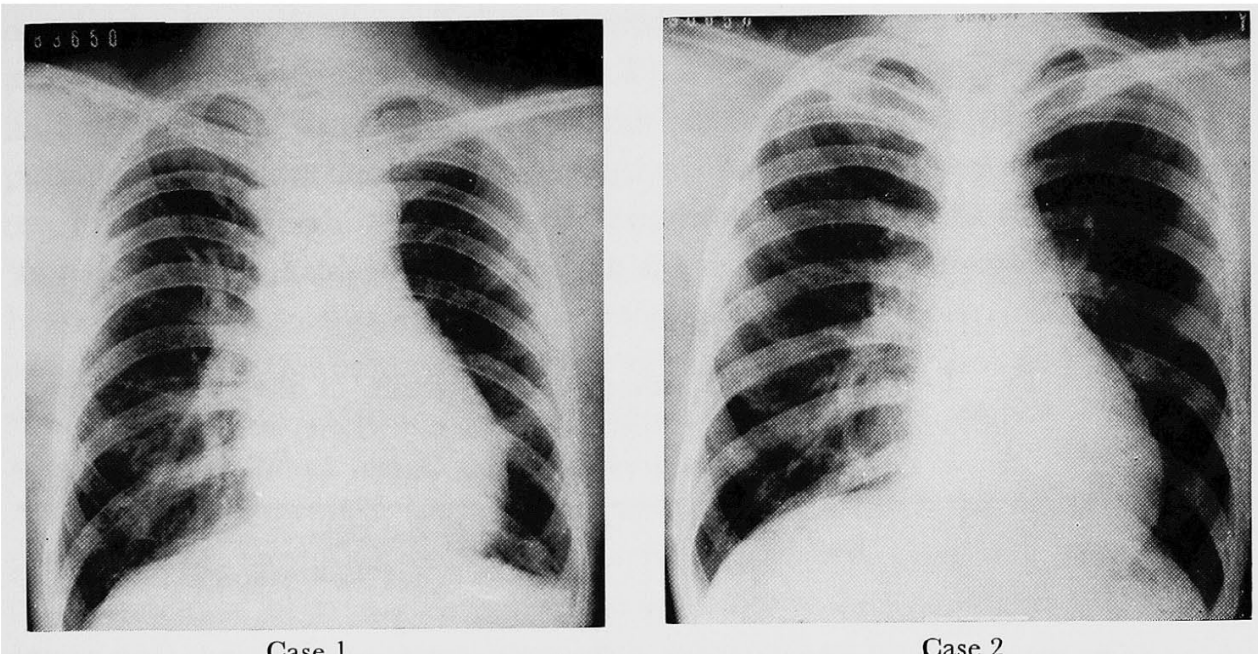

Case 1

Case 2

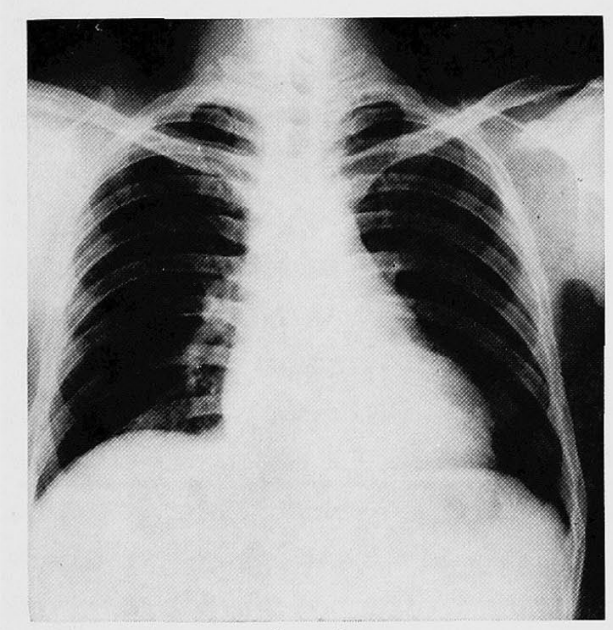

Case 3

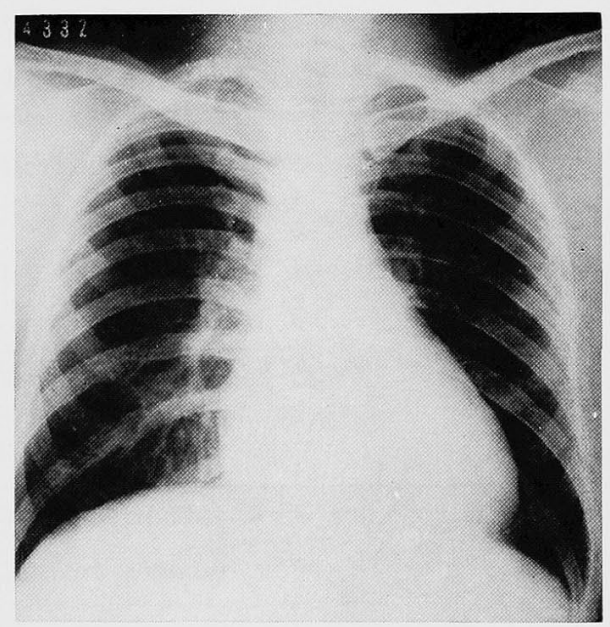

Case 4

Fig. 4. Postoperative chest X-ray films.

demonstrated in the beautiful histologic photograph by Edwards and Burchell, ${ }^{3)}$ is that the basic lesion is a lack of continuity between the aortic media and the ring of the aortic valve. The third is explained by the lack of firm tissue, probably due to an inborn deficiency of elastic tissue of the aorta, suggesting its some relation with the Marfan's syndrome. In fact, several cases with Marfan's stimgata have been reported.4),5) However, each of these theories is not satisfactory to explain simply by itself the development of aneurysm, contributing from various aortic sinuses to various directions. It must be considered that the etiology of this lesion might be two fold: 1) defective development of the aortic tissue at the base of the aorta, and 2) the constant stress of aortic pulsation on this weakened area, as Kiefer ${ }^{6}$ ) described. 
Soulie $^{7)}$ collected the most numbers of cases from the literature and arranged pathoanatomic observations (Table IV). Aneurysms of the aortic sinuses develop to the right ventricle and right atrium in 86 per cent of 100 cases, and aneurysms developed to the right ventricle are contributed from the right aortic sinus in 98 per cent and ones developed to the right atrium from the non-coronary sinus in 60 per cent and from the right coronary sinus in 32 per cent.

Table IV. Pathoanatomic Findings of Aneurysms of the Aortic

Sinus of Valsalva, Collected by Soulie (1964)

Positions of Aneurysms in 100 Cases

\begin{tabular}{lr|ll}
\hline Right ventricle & 52 & Left ventricle and right atrium & 1 \\
Right atrium & 34 & Left ventricle and right ventricle & 1 \\
Right atrium and right ventricle & 3 & Left atrium & 1 \\
Right ventricle and pulmonary artery & 1 & Pericardium and right atrium & 1 \\
Left ventricle & 4 & Cardiac septum & 2
\end{tabular}

Affected Aortic Sinuses and Positions of Aneurysms

\begin{tabular}{|c|c|c|c|c|c|c|c|}
\hline Sinus & No. & Rt. ventricle & Rt. atrium & $\begin{array}{l}\text { Rt. atrium } \\
\text { Rt. ventricle }\end{array}$ & $\begin{array}{l}\text { Lt. vent- } \\
\text { ricle }\end{array}$ & $\begin{array}{c}\text { Atrial } \\
\text { septum }\end{array}$ & $\begin{array}{c}\mathrm{Lt} . \\
\text { atrium }\end{array}$ \\
\hline Rt. coron. sinus & 60 & 44 & 8 & 2 & 6 & - & - \\
\hline Non-coron. sinus & 17 & 1 & 15 & - & - & 1 & -- \\
\hline Lt. coron. sinus & 3 & - & 2 & & & - & 1 \\
\hline Total & 80 & 45 & 25 & 2 & 6 & 1 & 1 \\
\hline \multicolumn{8}{|c|}{ Positions of Rupture } \\
\hline
\end{tabular}

$\frac{\text { Right ventricle } \ldots . .47 \text { cases }\left\{\begin{array}{l}\text { Infundibulum.....30 cases }(64 \%) \\ \text { Outflow tract.....17 cases }(36 \%)\end{array}\right.}{\left\{\begin{array}{l}\text { Superior to the tricuspid anterior commissure.....25 cases }(89 \%) \\ \text { Other portions.....3 cases }(11 \%)\end{array}\right.}$

Sakakibara and Konno ${ }^{8), 9)}$ classified it into 5 types, that is, types I, II, III-v, III-a and IV, and reported the incidence of each type, that is, type I 40 per cent, type II 6 per cent, type III-v 8 per cent, type III-a 21 per cent and type IV 23 per cent, respectively. Taguchi ${ }^{10)}$ added another type with the bicuspid aortic valve to their classification, and described the incidence of each type to be type I ( $58 \%$ ), type III-v, type II, his own type, type IV and type III-a in order. Present cases may be classified as follows; Case 2 is type I with VSD, Cases 1 and 5 are type II with VSD and Case 4 is type IV.

In frequently associated anomalies with this lesion, the ventricular septal defect hold an important position in embryologic development and the coarctation of the aorta is interested in some connection with mechanical development 
due to the constant stress of the aortic pulsation. In 46 cases with associated anomalies, collected by Soulie, there are 23 cases of ventricular septal defects, 23 cases of aortic valve anomalies, 3 cases of coarcted aortas, 2 cases of aortopulmonary fistulas, one case of pulmonary stenosis, one case of bicuspid pulmonic valve and one case of rheumatic mitral and tricuspid valvular disease. Ventricular septal defects are situated at the infundibulum in 15 cases, membranous septum in 5 cases and unknown in 3 cases. More than 50 per cent of aneurysms contributed from the right aortic sinus are associated with ventricular septal defects. In 23 cases with aortic valve anomalies, bicuspid aortic valve is found in 8 cases.

Cardiac murmurs have been previously indicated in 64 per cent of patients with ruptured aneurysm (Lockhart), ${ }^{11)}$ but there are rather many cases who have been not diagnosed to have heart disease before the onset of symptoms. Ages of the onset have been recorded to be widely ranged from 5 weeks to 3 or 4 decades of age, but the onset at infancy or early childhood is extremely rare. These aneurysms occur much more frequently in males than in females and more than 80 per cent of ruptured cases were male. ${ }^{6}{ }^{12}{ }^{12},{ }^{13}$ )

Congestive heart failures occur in 64 per cent of 76 patients, collected by Lockhart, ${ }^{11)}$ after the onset of the lesion, but severe symptoms as an attack appeared initially in only 37 per cent. Therefore, it is sometimes difficult to analyze the onset in the history.

Frequently observed clinical findings, as he described, are continuous or to-and-fro murmurs $(97.5 \%)$, cardiomegaly $(95 \%)$, increased pulmonary vascularization $(87 \%$ ), abnormal electrocardiograms $(84 \%)$, peripheral signs of aortic insufficiency $(83 \%)$ and congestive heart failure $(79 \%)$. Heart murmurs are the most valuable findings for the diagnosis and must be differentiated from the patent ductus arteriosus, the ventricular septal defect with aortic insufficiency, the pulmonary arteriovenous fistula, and the coronary arteriovenous fistula. They can be differentiated in most cases from the ruptured aneurysm of the aortic sinus by the intensity, the maximum point and radiation of murmurs, but the ventricular septal defect with aortic insufficiency is frequently difficult to differentiate from this disease.

The definite diagnosis requires special roentgenologic procedures, that is, the retrograde aortography. The diagnosis is confirmed by 1) early opacification of the pulmonary artery immediately after the opacification of the ascending aorta, 2) demonstration of regurgitant jet to the right sided heart from the aortic sinus and 3 ) direct opacification of the aneurysm, itself. Ventricular septal defect with aortic insufficiency can be mostly differentiated by this procedure.

The prognosis in patients with unruptured aneurysms is uncertain. 
After rupture, the prognosis is extremely poor in most cases, although the patient enters not infrequently an asymptomatic phase. Sawyers ${ }^{13)}$ described that the average age of death was 34.9 years of age and the mean survival time after the onset was 3.9 years, but if 2 patients of his collected 45 cases, who lived 10 and 15 years, respectively, were excluded, the average life expectancy was nearer 1 year. According to Lockhart, ${ }^{11}$ the survival time from the onset of the congestive heart failure was less than 3 months in $36 \%$ of 31 cases, from 3 months to 1 year in $26 \%$, from 1 to 2 years in $16 \%$ and over 2 years in $22 \%$. As a rule, death results from congestive heart failure and the second most common cause of death is bacterial endocarditis.

The ruptured aneurysm must be treated by surgery as soon as the diagnosis is established, but the indication for surgery must be decided deliberately according to stages of the disease. As experienced in Cases 3 and 4, it should be predicted that the operative mortality may be high in whose stage special examinations like cardiac catheterization or angiocardiography can not be performed.

There are 2 important problems in surgical aspect. The first is how to control regurgitation from the aorta to the operative field. The anoxic arrest with either general hypothermia or myocardial hypothermia by iceslush, or the coronary perfusion through combined aortotomy are used. This is closely related to the next problem. Present cases were all operated upon under anoxic arrest combined with general hypothermia. The second is how to repair the aneurysm. Recurrence of aneurysm or residual aortic insufficiency after surgery has occurred not infrequently. Therefore, Shumacker ${ }^{14}$ ) emphasized that it should be treated always bidirectionally through aortotomy and cardiotomy.

However, the aneurysm ruptured to the right atrium can be easily treated simply through the right atriotomy in fact, except the aneurysm with tortuous fistula, as described by Spencer. ${ }^{15)}$ Rather more attention should be payed not to injure the atrioventricular conduction system. On the other hand, the aneurysms ruptured to the right ventricle have been reported frequently difficult to correct completely, and the left-sided patch or the sandwitch-typed patch has been recommended through combined aortotomy by Sakakibara" and Taguchi. ${ }^{10}$ B But present cases were all completely corrected by direct mattress sutures with or without reinforcement only through the right-sided cardiotomy, and free from any sequelae of recurrence of aneurysm or residual aortic insufficiency in the follow-up period. Therefore, when the aneurysm can be excised at the healthy portion of the aortic sinus, the sinus may be tried first to close through the right-sided cardiotomy routinely.

Operative mortality is fortunately low, excluding cases with extremely severe cardiac failure. More than 150 patients with ruptured or unruptured 
aneurysms of the aortic sinus have been operated upon since 1955 in Japan ${ }^{1)}$ and the overall mortality is 14 per cent in 114 cases whose results were documented. Among these survivors, 15 patients were in sequelae with recurrence of aneurysm or residual aortic insufficiency, and this fact shows that the surgery of this lesion is not always easily undergone.

\section{SUMMARY}

(1) Five patients with the ruptured aneurysm of the aortic sinus were presented. They were all male and 27, 18, 14, 32 and 31 years of age, respectively. Four of them were treated surgically with success, but one patient died due to the progressive congestive heart failure before surgery.

(2) Operative findings revealed the aneurysm of the aortic sinus ruptured to the right ventricle in 3 cases and ruptured to the right atrium in 1 case. The additional ventricular septal defect adjacent to the aneurysm was associated with in each case in the former. Autopsy of the succumbed case was refused.

(3) Operative procedures were performed in all cases through the right-sided heart and their symptoms completely subsided. Neither recurrence of aneurysm nor residual aortic insufficiency could be demonstrated in followup.

(4) Etiologic mechanism, pathological anatomy, clinical features, prognosis and surgical treatment of the ruptured aneurysm of the aortic sinus were briefly discussed.

\section{AdDendum}

Since this paper was completed, we have had an additional experience of a 28-year-old woman with type I with VSD. The excised sinus defect was so large that the repair was accomplished by suturing a pericardial patch from within the aortic sinus through the defect. Her postoperative course was uneventful.

\section{REFERENGES}

1. Asano, K., Washio, M., Shiozaki, K., Eguchi, S., Matsuzawa, H., and Matsukawa, T.: Thoracic Surgery, in printed (in Japanese).

2. Jones, M. and Langley, F. A.: Brit. Heart J. 11 : 325, 1949.

3. Edwards, J. E. and Burchell, H. B. : Proc. Staff Meet. Mayo Clin. 31 : 407, 1956.

4. Heiner, D. G., Hara, M., and White, H. J.: Pediat. 27: 415, 1961.

5. Ainger, L. E. and Pate, J. W.: Am. J. Cardiol. 11 : 547, 1963 ,

6. Kieffer, S. A. and Winchell, P.: Dis. Chest 38: 79, 1960.

7. Soulie, P., Acar, J., Grosgogeat, Y., Cartier, F, and Vernant, P. : Arch. des Mal. du Coeur 57: 481, 1964 .

8. Sakakibara, S. and Konno, S.: Am. Heart J. 63: 405, 1962.

9. Sakakibara, S. and Konno, S.: Am. J. Cardiol. 12:100, 1963.

10. Takuchi, K.: J. Jap. Assoc. Thorac. Surg. 14: 553, 1966 (in Japanese)

11. Lockhart, A., Sceabat, L., and Lenegre, I.: Arch. des Mal. du Coeur 57: 508, 1964.

12. Oram, S. and East, T.: Brit. Heart J. 17: 54I, 1955.

13. Sawyers, J. L., Adams, J. E., and Scott, H. W., Jr. : Surg. 41 : 26, 1957.

14. Shumacker, H. B., Jr., King, H., and Waldhausen, J. A. : Ann. Surg. 161 : 946, 1965.

15. Spencer, F. G., Blake, H. A., and Bahnson, H. T.: Ann. Surg. 152: 963 , 1960. 